\title{
Fuel gases from pyrolysis of waste Polyethylene sachets
}

\author{
${ }^{1 *}$ ADEMILUYI, T; ${ }^{2}$ ADEBAYO, T A \\ ${ }^{1 *}$ Department of Chemical/ petrochemical Engineering, Rivers State University of Science and Technology, Port Harcourt. \\ ${ }^{2}$ Department of Petroleum Engineering, Rivers State University of Science and Technology, Port Harcourt.*
}

\begin{abstract}
Evaluation of fuel gases produced from pyrolysis of waste polyethylene was carried out. Waste polyethylene (pure water sachets) was pyrolysed at low and high temperatures. Pyrolysis of the waste for 300 secs at temperatures of $25^{\circ} \mathrm{C}-140^{\circ} \mathrm{C}$ produced $2.53 \%$ ethane, $21.67 \%$ propane and $75.82 \%$ propylene. The volume of the gaseous products at this low temperature is far less than the initial volume of the waste resulting into over $80 \%$ reduction in the volume of waste generated by discarding the polyethylene waste. Fresh samples of the waste were pyrolysed at higher temperature range from $50^{\circ} \mathrm{C}-250^{\circ} \mathrm{C}$ and cooled in a condenser. The non-condensable gas produced were collected and analyzed with Shimadzu gas chromatography. The analysis shows that $\mathrm{C}_{1}-\mathrm{C}_{6}$, and other alkenes and isoparaffins (18 ethylene monomers) were produced. The gaseous products being $75.82 \%$ propylene at low temperatures and $48.6 \%$ (normal and Iso) butane at higher temperatures. The flame test carried out shows that the gaseous products burns with a blue flame at lower temperature range. Above $300^{\circ} \mathrm{C}$ the flame becomes more luminous and production of fuel gases stops at $550^{\circ} \mathrm{C}$. Production of fuel oil from waste polyethylene led to production of large volume of gaseous products, some of which are non-condensable at room temperature. The gaseous products can serve as feedstock and as fuel gas. @JASEM
\end{abstract}

All around the world, it has been discovered that the average life span of man is in downward trend especially in the developing nations of the world. The major factor is the solid, liquid and gaseous wastes that serve as environmental pollutants. Presently the greatest environmental problem facing developing countries, especially Nigeria, is municipal and public waste management. The cities are stinking from heavy unmanageable solid waste. Due to the present economic situation in Nigeria, water is packaged in low-density polyethylene (LDPE) sachet that serves as the cheapest packaging material. It as become popular in almost all the communities but unfortunately this has led to new source of solid waste since the LDPE has extremely low rate of degradation.

The cheapest method for conversion of the LDPE waste to useful products is through pyrolysis. Pyrolysis process is assumed to take place as from $325^{\circ} \mathrm{C}$ and up to a maximum temperature of $850^{\circ} \mathrm{C}$ (Wilson, 1997). Gonzalez et al (2004) carried out the catalytic pyrolysis of polyethylene in spouted bed reactor and obtained products ranging from $\mathrm{C}_{2}$ to $\mathrm{C}_{9}$. It was concluded that the rate of weight loss is greatly influenced by the presence of catalyst. Nema and Ganeshphrasad (2002) studied the plasma pyrolysis of medical waste. Carbon II oxide (CO), hydrogen $\left(\mathrm{H}_{2}\right)$ and Carbon (IV) oxide $\left(\mathrm{CO}_{2}\right)$, as well as $\mathrm{C}_{1}-\mathrm{C}_{5}$ (i.e. $\mathrm{CH}_{4}, \mathrm{C}_{2} \mathrm{H}_{6}, \mathrm{C}_{3} \mathrm{H}_{8}, \mathrm{NC}_{4}$, IC5 NC5) were produced after pyrolysis. It was reported that $28 \mathrm{~g}$ of polyethylene produce $89.6 \mathrm{~L}$ of combustible gases. Tsuji et al (2001) gasified polyethylene, polypropylene and polystyrene plastic pellets in a two- stage thermal degradation process. The main component of the product gas for polyethylene and polypropylene were methane and olefins such as ethane and propene with some aromatic oils as by products.

Mastral et al (2001) studied the co-pyrolysis and cogasification of high-density polyethylene and saw dust mixture in a fluidized bed reactor. The main gases produced at low temperatures were carbon dioxide, carbon monoxide, ethylene propylene, butadiene and methane. At high temperature carbon monoxide, ethylene, methane, carbon dioxide, benzene and hydrogen were produced.

Ademiluyi and Akpan (2004) studied the production of fuel oil from pyrolysis of waste polyethylene (pure water sachets). Large volumes of gases, some of which are non-condensable at room temperature were produced . These gaseous products were discarded off as waste during the production of the fuel oil. The aim of this work is to study these non-condensable gases, and monitor it's production with time.

\section{MATERIALS AND METHODS}

MATERIALS: Polyethylene waste around the campus premises was gathered and the sample were washed in water to remove impurities like sand, and dried. Sample was cut into smaller bits to create higher surface area for pyrolysis.

The apparatus consists of a fabricated batch reactor, with lagging for effective heat transfer, thermocouple, mercury manometer, $750 \mathrm{ml}$ gas cylinder, electric heater and SHIMADZU gas chromatography. The arrangement is as shown in Fig 1. 
Pyrolysis At Low Temperature $\left(25^{\circ} \mathrm{C}-140^{\circ} \mathrm{C}\right)$ : The pure water sachet waste samples $(12.5 \mathrm{~g})$ were cut into small pieces and passed into the reactor through the hopper. The hopper was then properly sealed to avoid leakages before switching on the heater. The reaction time, temperature and pressure were measured as the reaction progresses. The gas collection was in the first 5 minutes as the temperature rises to $140^{\circ} \mathrm{C}$. There after pressure reduction was observed followed by production of dense white fumes suspected to be aromatic compounds. The gaseous product was sent to Shimadzu gas chromatography and was analysed using $20 \mathrm{ml}$ of helium as carrier gas and at column temperature range of $40^{\circ} \mathrm{C}$ to $180^{\circ} \mathrm{C}$. The detector was flame ionization Detector (FID) at $100^{\circ} \mathrm{C}$. Flame test was carried out and a colourless blue flame was obtained.

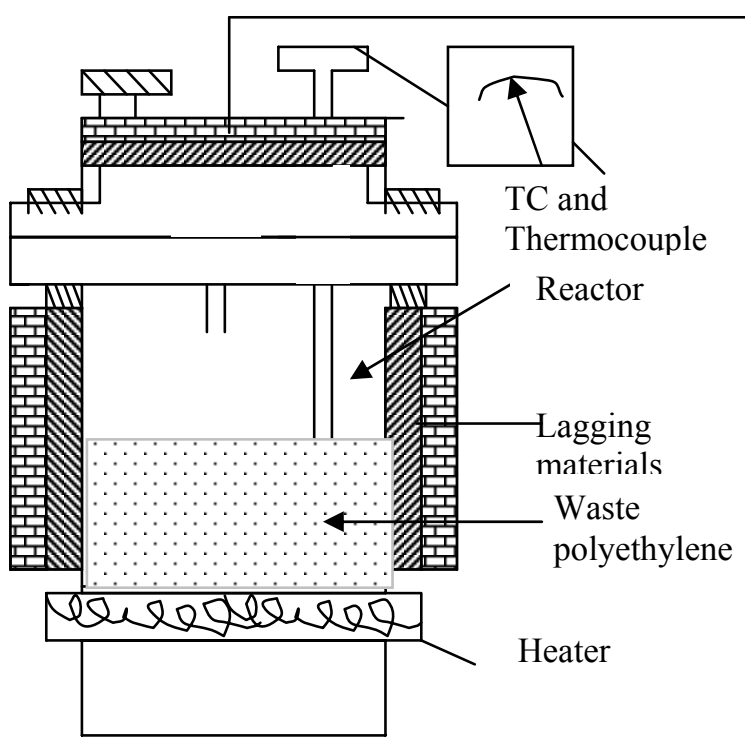

Fig 1. Reactor for pyrolysis

\section{EXPERIMENTAL PROCEDURES}

Pyrolysis at Higher Temperature $\left(50^{\circ} \mathrm{C}-250^{\circ} \mathrm{C}\right)$ : A fresh sample of waste pure water sachet of $8 \mathrm{~g}$ were washed, dried and cut in pieces and passed into the reactor through the hopper. The hopper was then properly sealed to avoid leakages before switching on the heater. The waste was pyrolysed until the reactor temperature rises to $250^{\circ} \mathrm{C}$. The reaction time, temperature and pressure were also measured as the reaction progresses further to $550^{\circ} \mathrm{C}$. The gaseous products obtained were passed through a condenser and cooled with water at $25^{\circ} \mathrm{C}$. The non-condensable gases were collected in a $750 \mathrm{ml}$ gas cylinder and analysed using the Shimadzu gas chromatography. Flame test was also carried out from $40^{\circ} \mathrm{C}$ to $550^{\circ} \mathrm{C}$.

\section{RESULTS AND DISCUSSION}

Pyrolysis At Low Temperature $\left(25^{\circ} \mathrm{C}-140^{\circ} \mathrm{C}\right)$ : Table 1 shows the effect of time and temperature on the pressure of gaseous product produced. The pressure of the gas increased with time and temperature, with the production of white fumes after $140^{\circ} \mathrm{C}$ by pyrolysing $12.5 \mathrm{~g}$ of waste. The gas chromatogram of the gaseous product produced from the waste between $25^{\circ} \mathrm{C}-140^{\circ} \mathrm{C}$ is presented in Fig 2 and Table 2 . The analysis shows that only ethane $2.52 \%$, propane $21.66 \%$ and propylene $75.82 \%$ were present. The results from Table 2 shows that during the production of wax from pyrolysis of pure water sachets (Ademiluyi et al, 2004) these gases were produced. This implies that the gaseous products produced during the formation of wax from the sachets are very useful. The flame test of the gaseous product in Table 4, carried out during the pyrolysis of the sachets from between $50^{\circ} \mathrm{C}-140^{\circ} \mathrm{C}$ shows the gases produced (ethane, propane, propylene) burns with a blue flame. 
Table 1: Time-Temperature / pressure data

\begin{tabular}{ccc}
\hline Time $(\mathrm{secs})$ & Temp $\left({ }^{\circ} \mathrm{C}\right)$ & Pressure $\left(\mathrm{N} / \mathrm{m}^{2}\right) \times 10^{-6}$ \\
\hline 0 & 25 & 1.01 \\
60 & 50 & 1.05 \\
120 & 60 & 1.09 \\
240 & 80 & 1.14 \\
270 & 110 & 1.21 \\
300 & 140 & 1.14 \\
\hline
\end{tabular}
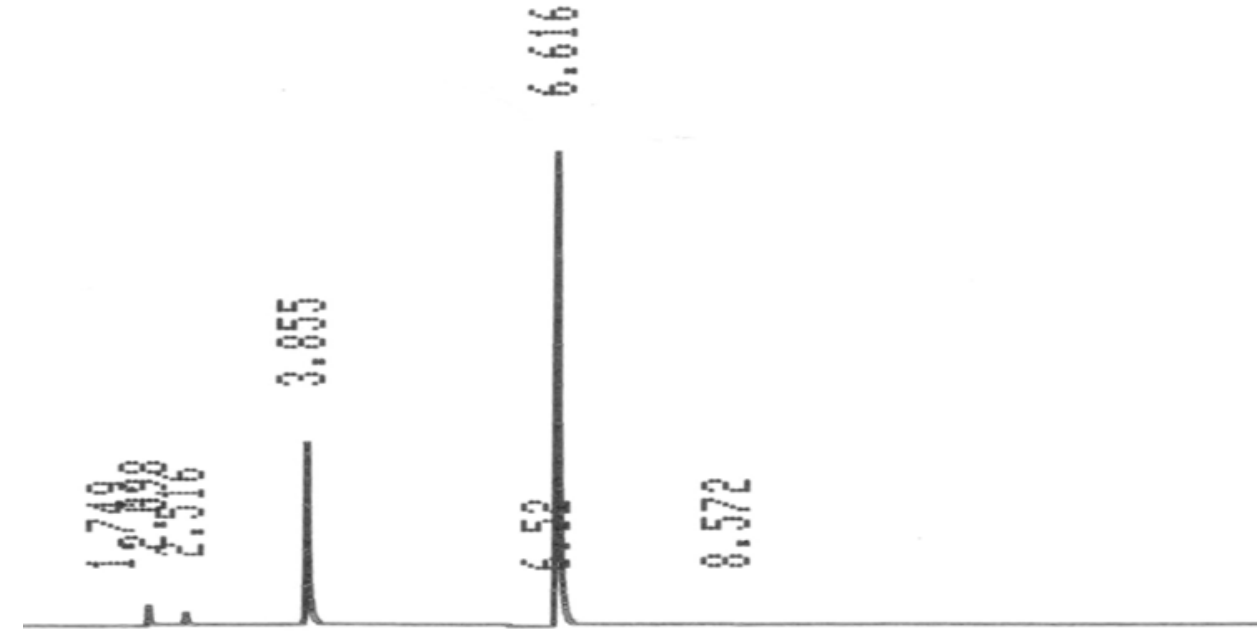

Fig 2 Retention time versus concentration for gaseous products $\left(25-140^{\circ} \mathrm{C}\right)$

Table 2: Gas Chromatography result of Analyzed gas $\left(25-140^{\circ} \mathrm{C}\right)$

\begin{tabular}{llllc}
\hline $\begin{array}{l}\text { Retention } \\
\text { Time } \\
\text { (mins) }\end{array}$ & Components & Names & $\begin{array}{l}\text { Concentration } \\
\left(\mathrm{mol} / \mathrm{dm}^{3}\right)\end{array}$ & $\begin{array}{c}\% \\
\text { Composition }\end{array}$ \\
\hline 2 & $\mathrm{C}_{2} \mathrm{H}_{6}$ & Ethane & 0.0040 & 2.5 \\
4 & $\mathrm{C}_{3} \mathrm{H}_{8}$ & Propane & 0.0344 & 21.7 \\
7 & $\mathrm{C}_{3} \mathrm{H}_{6}$ & Propylene & 0.1205 & 75.8 \\
\hline
\end{tabular}

Pyrolysis At Higher Temperature $\left(50^{\circ} \mathrm{C}-250^{\circ} \mathrm{C}\right)$ : The yield of the gaseous products increases with temperature and time from $50^{\circ} \mathrm{C}-550^{\circ} \mathrm{C}$ as shown in Fig 3. The yield of the non-condensable gases begins to drop from $550^{\circ} \mathrm{C}$. The result of the gaseous products obtained from pyrolysis of the sachets between $50^{\circ} \mathrm{C}-250^{\circ} \mathrm{C}$ shows that more gases were obtained. The pyrolysis of the waste polyethylene leads to the formation of new monomers.

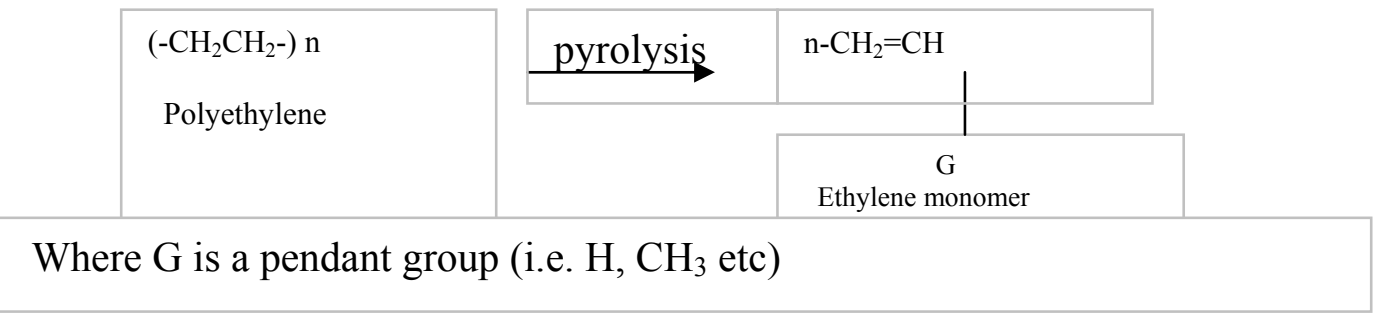


The chromatogram of the gaseous products obtained within temperature range of $50^{\circ} \mathrm{C}-250^{\circ} \mathrm{C}$ in Fig 4 and Table 3, shows that $\mathrm{C}_{1}-\mathrm{C}_{6}$ were present with some Isoparaffins, alkenes, 1,3 butadiene and methyl acetylene. This shows that the ethane, propane and propylene produced between $50^{\circ} \mathrm{C}-140^{\circ} \mathrm{C}$, must have undergo further reaction to form these 18 gaseous products at higher temperatures.

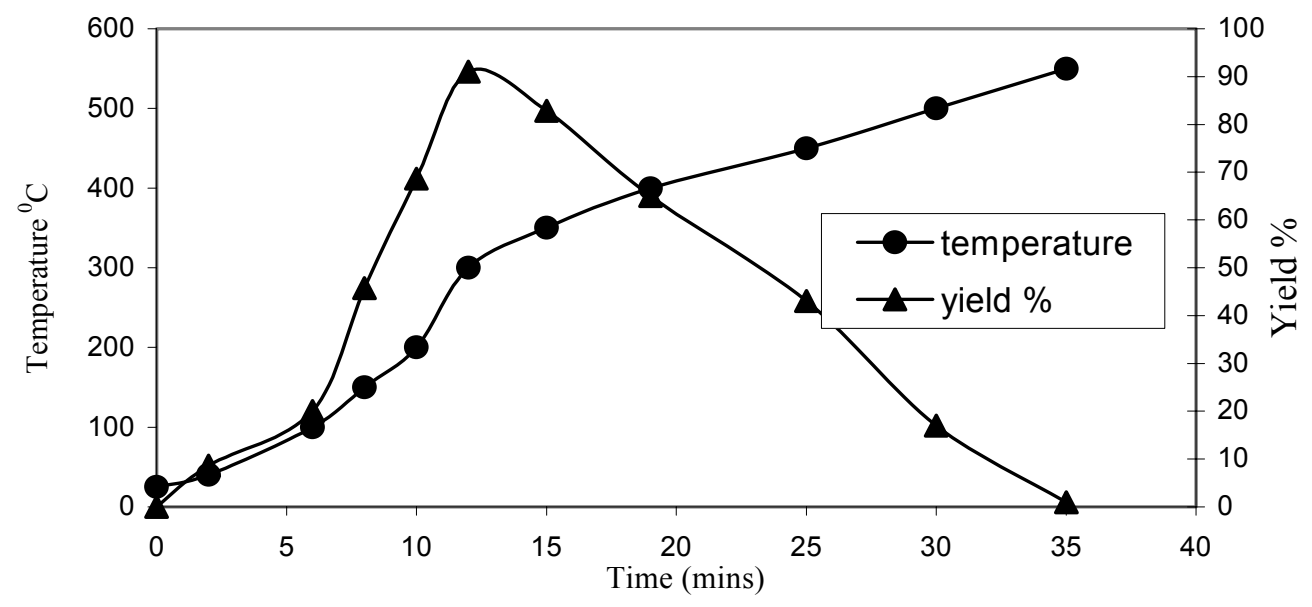

Fig 3 Effect of Temperature and time on the yield of gaseous products

Butane (comprising of Iso and normal butane) has the highest composition of $48.6 \%$, when the waste polyethylene sachets were pyrolysed from 50 $250^{\circ} \mathrm{C}$. Incineration of waste sachets in open air therefore constitutes toxic air pollution due to the production of $\mathrm{C}_{6}$ from temperatures above $250^{\circ} \mathrm{C}$ as shown in Table 3. Hence pyrolysis and proper condensation of these gases will best convert these waste sachets and produce useful non condensable gases shown in Table

Table 3: Analysis of non-condensable gaseous products $\left(50-250^{\circ} \mathrm{C}\right)$ with gas chromatography

\begin{tabular}{cccc}
\hline PKNO & Time & Composition & Compound \\
\hline 1 & 2 & 6.8 & $\mathrm{CH}_{4}$ \\
2 & 2. & 1.2 & $\mathrm{C}_{2} \mathrm{H}_{6}$ \\
3 & 3 & 2.2 & $\mathrm{C}_{2} \mathrm{H}_{4}$ \\
4 & 4 & 2.4 & $\mathrm{C}_{3} \mathrm{H}_{8}$ \\
5 & 7 & 3.4 & $\mathrm{C}_{3} \mathrm{H}_{6}$ \\
6 & 8 & 23.2 & Iso- $_{4} \mathrm{H}_{10}$ \\
7 & 9 & 25.4 & $\mathrm{n}_{4} \mathrm{C}_{4} \mathrm{H}_{10}$ \\
8 & 14 & 13.5 & t-2- $\mathrm{C}_{4}$ \\
9 & 15 & 9.1 & $1-\mathrm{C}_{4} \mathrm{H}_{8}$ \\
10 & 16 & 8.6 & $\mathrm{c}-2-\mathrm{C}_{4}$ \\
11 & 18 & 7.5 & Iso- $\mathrm{C}_{5} \mathrm{H}_{12}$ \\
12 & 21 & 0.5 & Methyl acetylene \\
13 & 22 & 0.5 & n-C $\mathrm{H}_{12}$ \\
14 & 23 & 0.5 & $1,3-\mathrm{Butadiene}_{2}$ \\
15 & 24 & 0.2 & C6PLUS \\
16 & 25 & 0.9 & C6PLUS \\
17 & 25 & 0.6 & C6PLUS \\
18 & 25 & 0.2 & C6PLUS \\
& TOTAL & 100 & \\
\hline
\end{tabular}




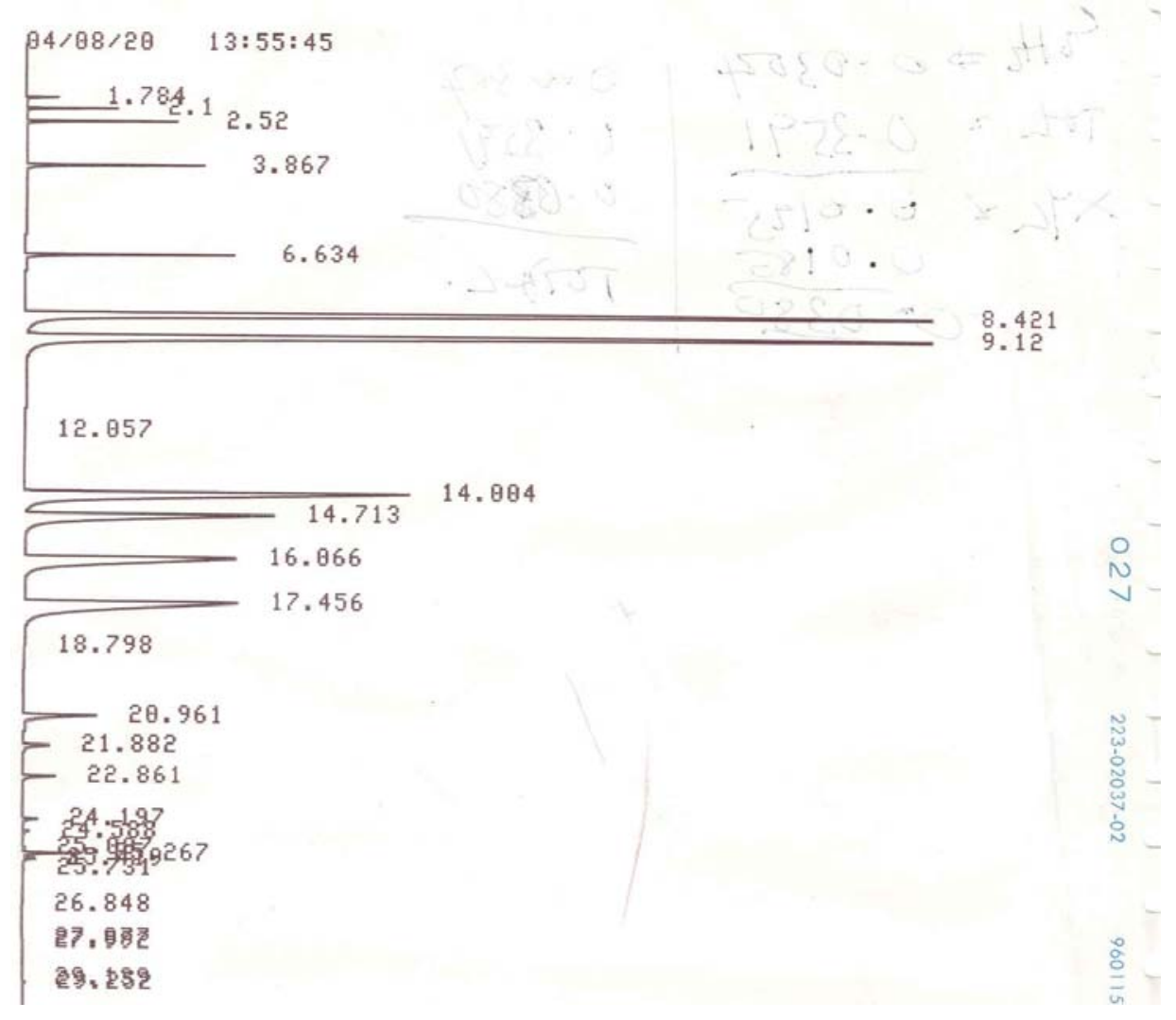

Fig 4 Retention time versus concentration for gaseous products $\left(50-250^{\circ} \mathrm{C}\right)$

FLAME TEST: Table 4 shows the summary of flame test carried out at different temperatures. At low temperatures the flame is non-luminous and burns continuously from $50^{\circ} \mathrm{C}-140^{\circ} \mathrm{C}$, with a pale blue flame. As the temperature increases the flame becomes more luminous (yellowish). At $400^{\circ} \mathrm{C}$ the gaseous product reduced and by $550^{\circ} \mathrm{C}$ no more gaseous product was produced. This shows that proper condensation of the gaseous products is required in order to produce clean gaseous fuels from the pyrolysis of the waste sachets.

Table 4: Summary of Flame Test

\begin{tabular}{cl}
\hline Temperature ${ }^{0} \mathrm{C}$ & Types of Flame \\
\hline $50-140$ & Burns with a blue flame \\
$150-200$ & Yellow flame appears on the blue flame \\
$200-300$ & Blue flame reduces with more yellow flame \\
400 & Bright yellow flame \\
$500-550$ & Yellow flame reduces gradually \\
\hline
\end{tabular}

Conclusion: Pyrolysis of low density polyethylene waste will not only reduce the solid waste by over $80 \%$ volume but will also result in production of $75.82 \%$ propylene gas at low temperature which can be used to produced polypropylene, another useful packaging material. At higher temperature, 48.57\% (iso and normal) butane was produced. These noncondensable gases produced during the formation of fuel oil from waste polyethylene can serve as feedstock and fuel gas. 


\section{REFERENCES}

Ademiluyi, T; Akpan, C. (2004) Production of fuel oil from pyrolysis of waste polyethylene (pure water sachets). In: Nigerian Society of Chemical Engineers Conf. Proc. 34, Port Harcourt, Nigeria, p.13-18.

Ademiluyi, T; Adebayo T A; (2004). Production of ethylene monomer from pyrolysis of polyethylene wastes. In: Nigerian Society of Chemical Engineers Conf. Proc. 34, Port Harcourt, Nigeria, p $107-112$.

Gonzalez, P; Prieto, R; Aguado, R; Olazar, M; Bilbao, J, (2002). Kinematics of polyethylene catalytic pyrolysis in a spouted bed reactor. In: Proceedings of $13^{\text {th }}$ International Congress on Catalysis, Paris France.
Nema, S K ; Ganeshprasad, K S (2002) Plasma pyrolysis of medical waste. Current Science. 83: $271-278$

Mastral, F J; Esperanza, E ; .Berrueco, C; Serrano, S; Ceamanos, J. (2001) Co-pyrolysis and Cogasification of polyethylene and sawdust mixtures in a fluidized bed reactor; temperature influence. In: Proceedings of the $5^{\text {th }}$ international Biomass Conference of the Americas, Florida USA.

Tsuji, Y; Tanaka, Y; Itoh, H. (2001). J. Material Cycles and Waste Management. 3:2-7.

Wilson, D.C. Waste (1997). Management, planning and evolution technologies, Claredon press, Oxford 